\title{
Acessibilidade, tecnologia assistiva e unidades de informação: articulações à realidade da inclusão
}

\author{
Daniela Francescutti Martins Hott ${ }^{I}$ \\ http://orcid.org/0000-0003-3945-9014 \\ Joeanne Neves Fraz ${ }^{I I}$ \\ http://orcid.org/0000-0001-8623-3769 \\ I Universidade de Brasília, Brasília, DF, Brasil \\ Doutoranda em Ciência da Informação. \\ II Universidade de Brasília, Brasília, DF, Brasil. \\ Doutoranda no Programa de Pós-Graduação em Educação.
}

http://dx.doi.org/10.1590/1981-5344/4194

O objetivo do estudo é refletir sobre acessibilidade e Tecnologia Assistiva, destacando aspectos legislativos pertinentes e observando a necessidade de sensibilizar profissionais das unidades de informação a buscarem uma formação técnico-sistêmica para atender às demandas de uma realidade inclusiva de forma transversal. Trata-se de um estudo de abordagem teórica e exploratória, pois parte da vivência das autoras nas disciplinas cursadas em seus programas de Pós-Graduação (Ciência da Informação e em Educação, Universidade de Brasília UnB), realização de seminários e reflexões sobre a realidade que a sociedade inclusiva e a acessibilidade apresentam às Unidades de Informação, tendo neste cenário as possibilidades da Tecnologia Assistiva. Os espaços públicos são para todas as pessoas, inclusive indivíduos com deficiência que possuem o direito de ir e vir.

Palavras-chave: Unidade de Informação. Acessibilidade. Tecnologia Assistiva. Sociedade inclusiva.

\section{Accessibility, assistive technology and information units: links to the inclusive existence}


The objective of the study is to reflect on accessibility and Assistive Technology, highlighting pertinent legislative aspects and observing the need to sensitize professionals from the information units to seek technical-systemic training to meet the demands of an inclusive existence in a transversal way. This is a theoretical and exploratory study, as part of the experience of the authors in the disciplines studied in their graduate programs (Information Science and Education, University of Brasilia - UnB), seminars and reflections on the a reality that inclusive society and accessibility present to the Information Units, having in this scenario the possibilities of Assistive Technology. Public spaces are for all people, including individuals with disabilities who have the right to come and go.

Keywords: Information Unit. Accessibility. Assistive Technology. Inclusive society.

Recebido em 12.11.2019 Aceito em 13.11.2019

\section{Introdução}

É fato que o uso da rede eletrônica por parte das instituições governamentais propicia maior rapidez de difusão das informações sobre as atividades e decisões tomadas, as quais podem ser acessadas tanto pelo cidadão comum, quanto pelos meios de comunicação de massa. Essa interlocução e/ou essa comunicação dos cidadãos com seus representantes eleitos, $e$, com as instituições governamentais se intensificou nos últimos anos. Todavia, por conta dos dispositivos legais que associados às Tecnologias de Informação e Comunicação (TICs), os órgãos governamentais instrumentalizaram-se na garantia desses conteúdos e serviços de forma desses conteúdos e serviços ser acessíveis a qualquer cidadão.

Enquanto a tecnologia é usada abundantemente, a eficácia de seu uso é colocada estritamente em termos humanos, até que ponto as aplicações tecnológicas permitem realmente, 0 eficiente acesso à informação e à comunicação. Os grandes sistemas de informação arriscam-se a disponibilizar tudo em ambiente web, entretanto há uma percepção, cada vez mais crescente, de usuários frustrados. Ainda assim, as questões não são técnicas somente, mas de cunho econômico, político, social e cultural. Para Oliveira, Alves e Maia (2013, p. 2), "[...] implica efetivamente em prestar um serviço informacional a alguém, sem restrição de cor, raça, status social, possíveis limitações, entre outros, pois a informação é um direito de qualquer cidadão que dela procura e/ou necessita". 
Talvez seja o momento de se considerar a busca por soluções e mecanismos que diminuam o isolamento e os conflitos entre os vários elementos da cadeia e propiciar maior grau de compatibilidade, para que os vários atores possam interagir com toda a potencialidade permitida pela moderna tecnologia e demandada pelas necessidades contemporâneas e futuras de informação (SARACEVIC, 1996, p.59).

No Relatório do Banco Mundial (2016) consta que a população mundial de pessoa com deficiência é composta por aproximadamente um sétimo do total mundial estimado, cerca de 1 bilhão de pessoas vivenciam uma realidade de significativa distância entre a disponibilização da informação e seu efetivo acesso, compreensão e utilização. Disponibilizar essas informações às pessoas com deficiência é atribuição sine qua non de autonomia plena que o Estado, por meio de suas instituições governamentais tem o dever de prover conforme conta na legislação em vigor e normativas internacionais. A informação tem valor fundamental atualmente, é matéria prima para a construção do conhecimento e para a formação de uma sociedade inclusiva e, quando levadas em conta as especificidades das pessoas, garante liberdade e autonomia.

No entanto, a literatura e a prática diária indicam que a falta de acessibilidade ainda prepondera, todavia ao indivíduo com deficiência, poder utilizar informações de forma autônoma, torna-se um dos caminhos para adquirir cidadania, visto que, de tal forma, conquista-se o direito de se integrar à sociedade, visando à diminuição de desigualdades, e a garantia de um futuro melhor. A Secretaria Nacional de Promoção dos direitos das pessoas com deficiência entende como acessibilidade:

Atributo essencial do ambiente que garante a melhoria da qualidade de vida das pessoas. Deve estar presente nos espaços, no meio físico, no transporte, na informação e comunicação, inclusive nos sistemas e tecnologias da informação e comunicação, bem como em outros serviços e instalações abertos ao público ou de uso público, tanto na cidade como no campo. (BRASIL, 2014).

Desde a aprovação da Convenção sobre os Direitos das Pessoas com Deficiência como emenda constitucional por meio do Decreto Legislativo no 186, de 2008 - este cidadão com deficiência cada vez mais tem conhecimento de seus direitos e deveres, e tem ido além do que é estabelecido no arcabouço legislativo, sobretudo, por conta do desenvolvimento de novos produtos, serviços, metodologias de Tecnologia Assistiva na educação, na saúde e no trabalho. Assim, marcando o caráter interdisciplinar da TA, uma área de conhecimento,

[...] que engloba produtos, recursos, metodologias, estratégias, práticas e serviços que objetivam promover a funcionalidade, relacionada a atividade e participação, de pessoas com deficiência, incapacidades ou mobilidade reduzida, visando sua autonomia, independência, qualidade de vida e inclusão social (BRASIL, 2009, p.9).

No Brasil, em diversos órgãos públicos, nos contratos de parceria público-privado, sobretudo nas empresas privadas, já há um olhar de 
integração das pessoas com deficiência em suas estações de trabalho. A obrigatoriedade desses contratos está embasada na Lei de Cotas - a Lei 8.213/1991 estabelece em seu artigo 93 que as empresas com 100 ou mais empregados a reservarem vagas para pessoas com deficiência, em proporções que variam de acordo com o número de empregados: de 100 a 200, a reserva legal é de 2\%; de 201 a 500, de 3\%; de 501 a 1000, de $4 \%$, e acima de 1001 , de 5\%. Embora haja legislação que respalde a contratação de pessoas com deficiência, há ainda um outro resultado que aponta a dificuldade do cumprimento do mínimo exigido em Lei, por conta ainda do despreparo das escolas - sejam elas públicas ou privadas - nas atividades de inclusão escolar.

Para exemplificar esse novo cenário, deve-se ressaltar também os resultados oriundos das implementações das políticas públicas para a educação inclusiva no Brasil. Para fins de ilustração, destaca-se o Censo Escolar da Educação Superior de 2004 a 2018 apresentado pelo Ministério da Educação (MEC) que vem apresentando um crescimento importante nas matriculas da educação especial nas classes comuns do ensino regular.

A promoção em acessibilidade é cada vez mais transversal, depreende-se do aparato jurídico brasileiro uma preocupação em proteger os direitos e fornecer garantias às pessoas com deficiência (PCD), "Documentos legais que embasam e garantem um atendimento adequado às necessidades específicas existem; é preciso deixar a passividade e colocar em prática tais diretrizes" (CONEGLIAN; SILVA, 2006, p. 12).

O presente trabalho faz parte das interlocuções vivenciadas no decurso dos Programas de Pós-Graduação em Ciência da Informação e em Educação na Universidade de Brasília (UnB), objetiva refletir sobre acessibilidade e Tecnologia Assistiva, destacando aspectos legislativos pertinentes e observando a necessidade de sensibilizar profissionais das unidades de informação a buscarem uma formação técnico-sistêmica para atender às demandas de forma transversal.

Estudo de abordagem teórica e exploratória, pois parte da vivência das autoras nas disciplinas cursadas em seus programas de PósGraduação (Ciência da Informação e em Educação, Universidade de Brasília - UnB), realização de seminários e reflexões sobre a realidade que a sociedade inclusiva e a acessibilidade apresentam às Unidades de Informação, tendo neste cenário as possibilidades da Tecnologia Assistiva.

Numa sociedade da informação e do conhecimento,

Não só as bibliotecas, museus, arquivos e centros de informação e documentação são considerados unidades de informação; diante das características e exigências da era da informação, também outras organizações e os diversos setores intraorganizacionais responsáveis pelo gerenciamento da informação documental e arquivística e das próprias TICs utilizadas institucionalmente, sejam elas organizações públicas, privadas ou do 30 setor (organizações não governamentais) (COSTA; SILVA; RAMALHO, 2010, p. 130). 


\section{Cenários da informação, acessibilidade e tecnologia assistiva}

Já é lugar comum considerar a informação como condição básica para o desenvolvimento econômico juntamente com o capital, o trabalho e a matéria-prima, mas o que torna a informação especialmente significativa na atualidade é sua natureza digital. A tecnologia não determina a sociedade: incorpora-a. Mas a sociedade também não determina a inovação tecnológica: utiliza-a. Essa interação dialética entre a sociedade e a tecnologia está presente nas obras dos historiadores, como Fernand Braudel.

Quando lemos o Oxford English Dictionary, encontramos dois contextos nos quais o termo informação é usado: o ato de moldar a mente e o ato de comunicar conhecimento. Ao ouvimos uma música, por exemplo, entre as disponibilizadas no Spotify (serviço de música digital que por meio de uma assinatura mensal o usuário tem a acesso a milhões de músicas), recebemos a informação musical a partir dos fones de ouvido do celular ou dos alto-falantes do carro. E, no momento que estamos ouvindo, apreciamos a música (a informação), ela desperta certos tipos de emoção dentro de nós.

Outro aspecto interessante, é que a cada vez, e a cada momento em que ouvimos de novo a mesma música, nossa relação com ela muda. A nossa emoção despertada pela música será sempre diferente, pois nossa percepção à música (informação) varia sempre de forma diversa no decorrer dos tempos e também por conta do nosso espírito naquele(s) momento(s) em particular. Em outras palavras, podemos usufruir da mesma informação inúmeras vezes, e em todos esses momentos, esta mesma informação chegará a nós de forma diferente.

Para Capurro e Hjorland (2007), o foco dos profissionais da informação implica uma abordagem sociológica e epistemológica para a geração, coleta, organização, interpretação, armazenamento, recuperação, disseminação, transformação e uso da informação. Pois todos os tipos de sistemas de informação têm políticas e objetivos mais ou menos explícitos, e o que os profissionais consideram como informação deveria também ser um reflexo da função social do sistema de informação. Mas o que se observa, é que "[...] a medida que os sistemas de informação tornam-se mais globais e interconectados, a informação implícita é, muitas vezes, perdida" (CAPURRO; HJORLAND, 2007, p. 194). Uma realidade que desafia a CI a ser mais receptiva aos impactos sociais e culturais dos processos interpretativos, que neste universo de diferenças qualitativas, entre diferentes contextos e mídias, impõe-Ihe um olhar mais interdisciplinar, que busca nas outras ciências, como a Educação, aspectos interpretativos que contemplem este conceito de informação ampliado, que traz consigo novos cenários de difusão e acesso.

As tecnologias avançadas no âmbito da informação em prol da cidadania têm de fato gerado mudanças na interação entre a sociedade e o Estado. Tem-se visto nas mídias e nas redes sociais, com uma frequência cada vez maior, a interlocução e/ou a comunicação dos 
cidadãos com seus representantes eleitos, e, com as instituições governamentais, e a recíproca também tem ocorrido. Por conta disso, cada vez mais, esses órgãos governamentais têm que se preocupar em garantir que esses conteúdos e serviços possam ser acessíveis a qualquer cidadão, e isto significa transpor barreiras e atitudes.

O uso da rede eletrônica por parte das instituições governamentais propicia maior rapidez de difusão das informações sobre as atividades e decisões tomadas, as quais podem ser acessadas tanto pelo cidadão comum, quanto pelos meios de comunicação de massa.

A síntese final indica, não um conflito, mas uma necessidade de equilíbrio. Existe uma certa "revolta do usuário" enquanto a tecnologia é usada abundantemente, a eficácia de seu uso é colocada estritamente em termos humanos. E a pergunta: "até que ponto as aplicações tecnológicas permitem realmente, o eficiente acesso à informação e à comunicação dos amplos estoques disponíveis de conhecimento?" Esta resposta transformase em questão fundamental e geralmente, esses pontos ficam perdidos em meio à sedução das aplicações tecnológicas, além da percepção crescente de usuários frustrados.

Saracevic (1996) apontava que não importa se a atividade que trata dessas questões seja chamada de CI, informática, ciências da informação, estudos de informação, ciências de computação e da informação, inteligência artificial, ciência da informação e engenharia, biblioteconomia e ciência da informação, ou qualquer outra forma, o que diferencia é o foco dos problemas em usuários humanos e não em aspectos tecnológicos.

A acessibilidade se insere na política de inclusão social e, nesse sentido, pode ser definida como a condição para a utilização, com segurança e autonomia, dos espaços, mobiliários e equipamentos urbanos, das edificações, dos transportes e dos sistemas e meios de comunicação por pessoas com deficiência ou com mobilidade reduzida.

Conforme consta na Constituição Federal Brasileira, na Convenção sobre os Direitos das Pessoas com Deficiência assinada em Nova York, em 30 de março de 2007 e na Lei Brasileira de Inclusão da Pessoa com Deficiência, no Brasil, em 2015, ratifica-se a Convenção sobre o Direito das Pessoas com Deficiência (CDPD) da ONU em 2008, outro marco fundamental na trajetória da educação inclusiva no Brasil. O artigo 24 reafirma que a educação inclusiva torna-se um direito inquestionável, incondicional e inalienável, além de garantir plenas condições de acesso, permanência, participação e aprendizagem, na educação básica, ela determina que os Estados partes deverão assegurar que as pessoas com deficiência possam ter acesso à educação superior e profissional.

O capítulo II que trata do acesso à informação e à comunicação da LBI, determina que o poder público deve assegurar a disponibilidade e o acesso às informações, sejam elas virtuais e(ou) não, de forma que toda pessoa com deficiência possa usufruir do seu direito de acesso, inclusive ofertando ambientes adequados e acessíveis, e recursos assistivos como subtitulação por meio de legenda oculta (closed caption), janela com intérprete da Libras e audiodescrição: 
A política governamental brasileira voltada para a TA sinaliza para o atendimento das deficiências dos sujeitos, reconhecendo seus direitos de cidadãos em receber os recursos os quais demandam. (FRAZ, 2018, p. 531).

Dentre diversos dispositivos legais, cita-se o Decreto no 5.296/2004, que regulamenta a Lei no $10.048 / 200$, que dá prioridade de atendimento às pessoas com deficiência e a Lei no 10.098/2000, que estabelece normas gerais e critérios básicos para a promoção da acessibilidade das pessoas com deficiência, determina em seu artigo $5^{\circ}$ que o pessoal do quadro deverá ser capacitado para prestar atendimento diferenciado e imediato às diferentes categorias de pessoas com deficiência (auditiva, física, mental e visual) e também aos idosos.

Ainda o Decreto no 5.296/2004, em seu capítulo VI que trata do acesso à informação e à comunicação, o artigo 47 estabeleceu que "[...] no prazo de até doze meses a contar da data da publicação - 02 de dezembro de 2004 - será obrigatória a acessibilidade nos portais e sítios eletrônicos da administração pública na rede mundial de computadores (internet), para o uso das pessoas com deficiência". Este normativo estabelece vários dispositivos pautados nas normas da Associação Brasileira de Normas Técnicas (ABNT) no que se refere à implementação de acessibilidade arquitetônica e urbanística, da acessibilidade aos serviços de transportes coletivos, e do acesso à informação e à comunicação.

Tem-se, também, ainda no Decreto no 5.626/2005, que regulamenta a Lei no 10.436/2002, que dispõe sobre a Língua Brasileira de Sinais - Libras, estabelece em seu artigo $26 \S 1^{\circ}$, que os órgãos públicos "[...] devem dispor de, pelo menos, cinco por cento de servidores, funcionários e empregados capacitados para o uso e interpretação da Libras".

Tem-se conhecimento de que a Lei no 12.527/2011 ou Lei de Acesso a Informação - LAI (BRASIL, 2011) estabeleceu procedimentos para garantir o direito a informação, consagrado constitucionalmente. $O$ olhar da implementação e da efetivação desse direito deve se dar em consonância com a LBI. A LAI (BRASIL, 2011) regulamentou o acesso e a disponibilização ao público de informações de interesse coletivo ou geral, independente de requerimento. Além disso, a referida Lei regulou os mecanismos para o atendimento dos pedidos de acesso à informação apresentados pela sociedade, a chamada transparência passiva. Cuidou também das hipóteses, sempre excepcionais, de classificação da informação em graus de sigilo, tendo como pressuposto a segurança da sociedade e do Estado.

A Lei 8.159/1991 que dispõe sobre a política nacional de arquivos públicos e privados, conhecida como a Lei de Arquivos, juntamente com a LAI (BRASIL, 2011) e a LBI, subentende que as questões sobre o acesso à informação governamental estão intimamente relacionadas às ações de transparência administrativa e ao direito de acesso às informações 
governamentais. Há ainda, implicações de ordem estrutural no que diz respeito ao atendimento dos pedidos e fornecimento em prazo hábil das informações solicitadas; grande parte dos conteúdos informacionais está disperso nos diversos órgãos públicos sem que haja tratamento adequado para fins de disponibilização ao grande público. Isso sem falar em conjuntos informacionais não sistematizados ou documentados, existentes apenas como formas esparsas detidas por um e outro sujeito, não havendo sobre elas qualquer controle ou conhecimento coletivo de sua existência, além de não oferecerem nenhum.

Conforme Hott e Oliveira (2014, p.35):

[...] as instituições arquivísticas dos governos mais avançados, ao contrário do que predomina no Brasil, não tratam apenas de conservar e tornar acessíveis os atos do passado. Trata-se de órgãos muitas vezes ministeriais com múltiplas funções de apoio à gestão pública e à produção do conhecimento científico e tecnológico. São também territórios da memória coletiva, cultura e cidadania.

No contexto da Biblioteconomia, em março de 2016, a Presidente da Federação Brasileira de Associações de Bibliotecários, Cientistas da Informação e Instituições (FEBAB), Adriana Ferrari, participou na mesa "A Formação do Bibliotecário e a Biblioteca para Todos: a acessibilidade em questão" que ocorreu na Biblioteca Brasiliana Guita e José Mindlin, da Universidade de São Paulo (USP), quando foram apresentados os resultados do Projeto Acessibilidade em Bibliotecas Públicas resultado da parceria do Ministério da Cultura (MinC) com a ONG Mais Diferenças, organização da sociedade civil de interesse público que atua há uma década com educação e cultura inclusivas. O evento foi promovido pelo MinC, por meio do Sistema Nacional de Bibliotecas Públicas (SNBP) da Diretoria do Livro, Leitura, Literatura e Bibliotecas (DLLLB), e a ONG Mais Diferenças, como uma das vertentes da área da Biblioteconomia em prol da Acessibilidade (FEDERAÇÃO, 2016). Destarte, afirma-se a necessidade de as bibliotecas articularem-se à questão da acessibilidade, "A biblioteca acessível é aquela que envolve a acessibilidade física e informacional, oferecendo um serviço adequado que trabalhe as habilidades dos usuários com NEE no uso da informação" (EUGÊNIO, 2011, p.23), garantindo acesso à informação para todos, independente de deficiência ou limitações, mas conforme suas especificidades (CONEGLIAN; SILVA, 2006; OLIVEIRA; ALVES; MAIA, 2013).

No âmbito da Museologia, a II Conferência Nacional de Cultura (CNC) foi realizada em fevereiro de 2010, no Rio de Janeiro, com a PréConferência de Museus e Memórias, e a participação de representantes de 26 unidades da Federação, a fim de subsidiar o processo de construção de um plano setorial voltado para o setor museal, tendo no eixo II da Cultura, cidade e cidadania, "[...] a preparação do ambiente legal e dos museus de forma a garantir plano e práticas de acessibilidade universal" (BRASIL, 2010, p. 16). De acordo com Tojal (2007, p. 45), 
O espaço museológico pode perfeitamente conduzir um processo de inclusão na medida em que disponibilize sua cultura objetivada não apenas para a contemplação, mas principalmente para aparelhar um processo comunicativo que situe as pessoas no seu próprio 'habitat', dinamizando novas relações nos mais diferentes espaços em que vivem essas mesmas pessoas, com, e não apesar de, sua diversidade.

Araújo (2014, p. 97) destaca ainda que:

[...] as perspectivas desenvolvidas no século $X X$ foram importantes para deslocar e ampliar o eixo de preocupações da Ciência da Informação para as funções sociais dos arquivos, bibliotecas e museus, seu papel nos conflitos sociais, as apropriações dos sujeitos, os efeitos de sentido gerados por seus acervos e pelas técnicas aplicadas.

Entende-se que a acessibilidade é um processo dinâmico associado, principalmente, ao desenvolvimento da sociedade: uma sociedade inclusiva com sujeitos protagonistas, responsáveis e corresponsáveis para a não exclusão das diferenças, da diversidade. Para Albuquerque, Sousa e Guimarães (2015, p. 44),

Garantir a acessibilidade estrutural (aspectos físicos ou de infraestrutura) e informacional (digital) aos usuários é fundamental para democratizar o acesso e uso da informação disponibilizada nos diversos contextos analisados.

\section{Discussão: articulações à realidade da inclusão}

O acesso à informação contribui para o desenvolvimento da sociedade, gerando novas possibilidades para as pessoas, tornando-as aptas a construir uma sociedade mais justa e igualitária. Uma forma de propiciar o uso da informação pela sociedade em geral é que ela seja disponível e de fácil acesso. Essa disponibilidade deve estar apoiada em ações que permitam conhecer o que há e onde está, que os usuários saibam o que existe sobre o assunto de seu interesse e como obtê-lo.

Assim, o papel das unidades de informação como instituições sociais responsáveis pela realização e promoção de práticas informacionais, de exigência políticosocial e epistemológica, cujo acesso mais justo e democrático, converte estas práticas informacionais em

[...] práticas sociais, culturais e educativas de tratamento, organização e comunicação da informação, como geração, transferência, difusão/disseminação, armazenamento, recuperação e uso da informação" (COSTA; SILVA; RAMALHO, 2010, p. 130).

Acessibilidade e Tecnologia Assistiva se articulam neste contexto que aponta para a necessidade de profissionais que acompanhem o avanço acelerado das tecnologias da informação (e assistiva), bem como da acessibilidade virtual. Destacando, assim, como as mudanças sociais, econômicas e políticas ocorridas desempenham 0 atendimento aos 
usuários da informação em geral e, em especial, às pessoas com deficiência, com competência inclusive no âmbito informacional. Não mais com enfoque na barreira arquitetônica, mas na virtual, que apresenta recursos e ferramentas assistivas de acesso a esta informação.

No contexto da internet, a flexibilidade da informação e a interface entre o usuário e o respectivo suporte de apresentação caracterizam a acessibilidade. A flexibilidade da informação, nesse contexto, refere-se ao uso da informação por pessoas com necessidades especiais através de vários equipamentos ou navegadores em diferentes ambientes e situações (CERTIC, 2009 apud COSTA; SILVA; RAMALHO, 2010, p. 138).

Neste cenário de/da acessibilidade, o mercado exige hoje profissionais do campo da Ciência da Informação com conhecimentos abrangentes e transversais, que possa aplicar ações flexíveis, seja sensível às mudanças, apresente habilidades para enfrentamento de momentos decisórios, e detenha domínio sobre os equipamentos tecnológicos, em prol da acessibilidade física, auditiva, visual, táctil e virtual. Torna-se importante que o profissional da informação reflita sobre os desafios no processo da construção de uma sociedade inclusiva, priorizando justiça, a equidade e o acesso e uso democrático da informação, com responsabilidade social.

\section{Considerações finais}

Hoje, todos os envolvidos estão aprendendo a entender, a mudar, a pensar diferente, a ousar e a fazer diferente. Em todas as profissões, todos os envolvidos tem que estar disponíveis para enfrentar inovações e se capacitar para atender às exigências da atualidade, incluindo as questões de acessibilidade integral. O preparo dos profissionais passa, necessariamente, pela valorização de sua formação e pela necessidade de estratégias de combate à exclusão das pessoas com deficiência, tanto nos espaços de informação quanto na educação (MOREIRA; MARINQUE, 2014).

Os espaços públicos são para todas as pessoas, inclusive indivíduos com deficiência que possuem o direito de ir e vir. Então, trata-se de um exercício de adaptação diário, e para cada situação e contexto. É um grande quebra-cabeça que precisa ser montado por muitas mãos, com paciência, persistência e muita criatividade. O olhar é o do outro, sempre.

Este trabalho refletiu sobre acessibilidade e Tecnologia Assistiva, destacando aspectos legislativos pertinentes e observando a necessidade de sensibilizar profissionais das unidades de informação a buscarem uma formação técnico-sistêmica para atender às demandas de forma transversal. Um diálogo estabelecido com base nas experiências, leituras e debates vivenciados em dois Programas de Pós-Graduação da Universidade de Brasília (UnB), Ciência da Informação e Educação, que destaca a importância da acessibilidade e do papel de cada indivíduo nesta realidade: por acreditar que são vários os sujeitos e corresponsáveis pela inclusão! 


\section{Referências}

ALBUQUERQUE, M. E. B. C.; SOUSA, M. R. F.; GUIMARÃES, I. J. B. Organização da informação e acessibilidade para usuários deficientes visuais em bibliotecas, arquivos, museus e web. Biblionline, João Pessoa (PB), v. 11, n. 2, p. 43 - 56, 2015.

ARAUJO, C. A. A. Arquivologia, biblioteconomia, museologia e ciência da informação: o diálogo possível. Brasília, DF: Briquet de Lemos, 2014.

ARAÚJO, C.A.A. O que é Ciência da Informação? Inf. Inf., Londrina (PR), v. 19, n. 1, p. $01-30$, jan./abr. 2014. Disponível em:

http://www.uel.br/revistas/uel/index.php/informacao/article/viewFile/15958/14205. Acesso em: 10 mai. 2019.

BERSCH, R. Introdução à Tecnologia Assistiva. Assistiva - Tecnologia e Educação, Porto Alegre (RS), 2017. Disponível em:

http://www.haasfretes.com.br/arquivos/introducao-tecnologia-assistiva.pdf. Acesso em:

10 mai. 2019.

BRASIL. Subsecretaria Nacional de Promoção dos Direitos da Pessoa com Deficiência. Tecnologia Assistiva. 2008. Disponível em:

http://www.pessoacomdeficiencia.gov.br/app/publicacoes/tecnologia-assistiva. Acesso em 16 out. 2017.

BRASIL. Lei no 12.343, de 2 de dezembro de 2010. Institui o Plano Nacional de Cultura - PNC, cria o Sistema Nacional de Informações e indicadores Culturais - e dá outras providências. Brasília, 2010.

BRASIL. Lei no 12.527, de 18 de novembro de 2011. Disponível em: http://www.planalto.gov.br/ccivil_03/_ato2011-2014/2011/lei/112527.htm. Acesso em: 08 mai. 2019.

CAPURRO, R.; HJORLAND, B. O conceito de informação. Perspectivas em Ciência da Informação, v. 12, n. 1, p. 148-207, jan./abr. 2007. Disponível em: http://www.scielo.br/pdf/pci/v12n1/11.pdf. Acesso em: 05 mai. 2019.

CONEGLIAN, A. L. O.; SILVA, H. C. Biblioteca inclusiva: perspectivas internacionais para o atendimento a usuários com surdez. In: Encontro Nacional de Pesquisa em Ciência da Informação, 7, 2006, Marília (SP). Anais [...] Marília (SP): ANCIB, 2006. Disponível em: http://enancib.ibict.br/index.php/enancib/viienancib/paper/viewFile/2485/1616. Acesso em: 09 mai. 2019.

COSTA, L. F.; SILVA, A. L. P.; RAMALHO, F. A. Para além dos estudos de uso da informação arquivística: a questão da acessibilidade. Ci. Inf., Brasília, DF, v. 39 n. 2, p.129-143, maio/ago., 2010. Disponível em: http://www.scielo.br/pdf/ci/v39n2/11.pdf. Acesso em: 10 mai. 2019.

EUGÊNIO, J. E. S. Acessibilidade para estudantes com necessidades especiais: estudo de caso da Biblioteca Central Zila Mamede da Universidade Federal do Rio Grande do Norte. 2011. 52f. Monografia (Graduação em Biblioteconomia) - Universidade Federal do Rio Grande do Norte, Centro de Ciências Sociais Aplicadas, Natal, 2011. Disponível em: 
http://repositorio.ufrn.br:8080/monografias/bitstream/1/208/6/JoseESE_Monografia.pdf. Acesso em: 09 mai. 2019.

FRAZ, J. N. Tecnologia Assistiva e Educação Matemática: experiências de inclusão no ensino e aprendizagem da Matemática nas deficiências visual, intelectual e auditiva. Revista de Educação Matemática, São Paulo, v. 15, n. 20, p. 523-547, set. /dez. 2018.

HOTT, D. F. M.; OLIVEIRA, L. P. Aspectos intervenientes da Lei de Acesso à Informação no processo de gestão documental nas organizações. Acesso Livre, n. 2 jul./dez. 2014, p. 33-52. Disponível em:

https://revistaacessolivre.files.wordpress.com/2015/09/daniela-francescutti-martins-hott1.pdf. Acesso em: 05 mai. 2019.

MOREIRA, G. E.; MARINQUE, A. L. Percepções de Professores acerca da Inclusão de Alunos com NEE em Aulas de Matemática em Braga (Portugal) e no Distrito Federal (Brasil). Perspectiva da Educação Matemática. Revista do Programa de Pós-Graduação em Educação Matemática da Universidade Federal de Mato Grosso do Sul (UFMS). V. 7, N. 14, 2014.

OLIVEIRA, M. A. D.; ALVES, M. V.; MAIA, M. A. Q. A função social do profissional da informação numa biblioteca inclusiva. XXV CONGRESSO BRASILEIRO DE BIBLIOTECONOMIA, DOCUMENTAÇÃO E CIÊNCIA DA INFORMAÇÃO. Florianópolis, SC, Brasil, 07 a 10 de julho, 2013.

SARACEVIC, T. Ciência da informação: origem, evolução e relações. Perspectivas em Ciência da Informação, Belo Horizonte (MG), v. 1, n. 1, p. 41-62, jan./jun. 1996.

TOJAL, A. P. F. Políticas Públicas de Inclusão de Públicos Especiais em Museus. 322f. 2007. Tese (Doutorado em Ciência da Informação. São Paulo: Escola de Comunicação e Artes da Universidade de São Paulo, 2007. 